\title{
Research on Book Purchasing Process Based on ERP
}

\author{
$\mathrm{Ke} \mathrm{Ma}$ \\ Library \\ China Jiliang University, Hangzhou, China, 310018 \\ ma54keke@163.com
}

\begin{abstract}
The purchase of library management system under ERP is studied in this paper. First, the book purchasing process based on ERP is introduced. Then, the ERP system implementation of book purchasing process is studied, which include purchasing plan making, good cooperation with suppliers, order management in library, order tracking and expediting and the acceptance of goods. Finally, the ERP system to improve the purchasing process of library is analyzed.
\end{abstract}

Keywords-ERP; purchasing process; order tracking; purchasing plan making; order management

\section{INTRODUCTION}

Enterprise resource plan (ERP) is a kind of thought about enterprise management, which sets purchase, sales, production, finance, quality management in one, makes rational planning and controls each link with the development of computer technology and communication technology. In order to make the human resources, financial resources, material resources and other resources to be shared and utilized accurately and in time, ERP makes corresponding adjustments according to the changing market demand, so that costs can be reduced, efficiency and the quality can be improved[1][2]. The ERP system helps the library to be constructed in a scientific way and directs what kind of books and how many books are to be purchased, so that limited purchase funds can be used well to meet the needs of readers and the function of the library can be more fully realized.

Many domestic scholars study the work of ERP by using library management system. The research shows that the application of the management idea of ERP into library management can increase the library's benefits and work efficiency, and strengthen its service ability and optimize its component factors [3]. In [4], the authors propose library resource planning (LRP) with the aid of ERP, which is based on supply chain management (SCM). The components of LRP and information flow in library system is studied. In [5], the authors studies library's current situation, then analyze ERP manage theory, and at last raise countermeasures for problems in implementing ERP is paying attention to library leaders' strong support and is choosing the most suitable ERP products. Some concrete countermeasures are proposed in [6], which includes scientifically distributing the book purchasing outlay, strengthening the purchase to e-book and acoustic and image datum, widening purchasing channel. In [7], the authors propose the strategy of choosing book wholesalers in university library with the characteristics of university library, which includes previous research, the number of booksellers, state-owned and private booksellers, and so on. The ERP system using library management system based on database is introduced in [8], whose main function is to manage the matters about the readers, books, borrowing, returning, extended lists, and so on. In [9], the authors attempt to design a Shanghai foreign language education press (SFLEP) proper ERP system, which centers on finance. To be exact, the four main branches of the press (editing, printing, storing, and marketing) should all be combined with the finance department to optimize the flow of capitals.

This paper focuses on the purchase management system of library under ERP. That is, how to manage the literature information resources of library, which accounts for the absolute proportion of library funds. Library Purchasing does no longer regard the library literature information simply as a commodity to be bought, but as a complicated system. It is a process of formulating purchase activities according to the existing collections, the user requirements and the long-term development plan $\mathrm{s}$ for library literature resource.

\section{BOOK PURCHASING PROCESS BASED ON ERP}

The purchasing process starts in a certain demand for materials. In order to effectively meet the demand of each department and promote the normal operation, for the purchasing department, it's important to identify and determine certain goods need [10]. The purchasing process in ERP system is shown in Fig. 1. It can be drawn from the Fig. 1 that in ERP system, the purchase needs the cooperation of financial personnel, purchase and warehouse personnel. They finish the purchasing together in the purchase system and the inventory accounting system. At the same time, they work for a unified management of purchase requisition, budget, purchase orders, and settlement. The return in the purchase process is also to be managed. Until the goods are put into the 
warehouse and the warehouse receipts are gotten, the purchasing process is completed.

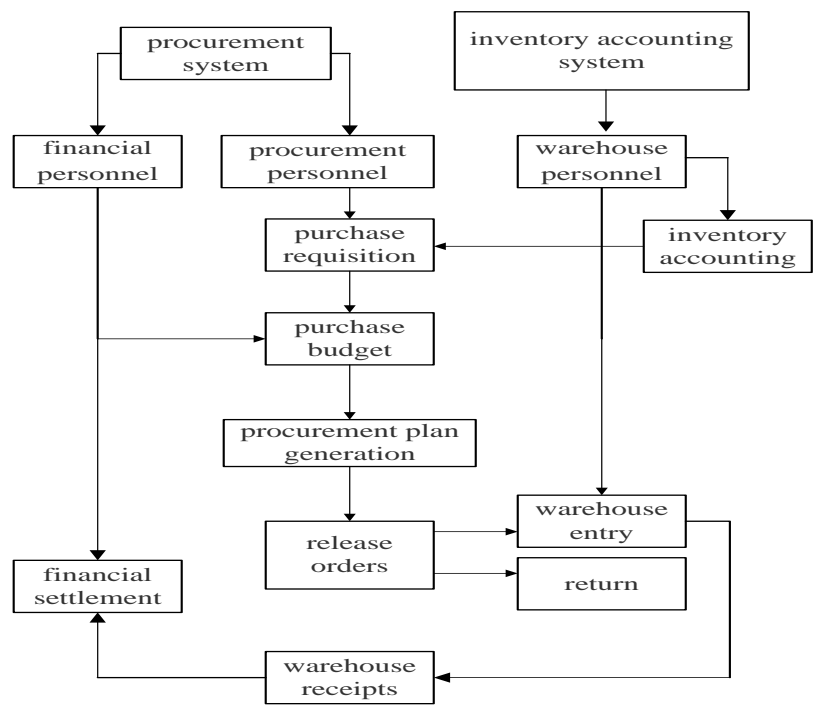

Figure 1. ERP purchase system flow

\section{THE IMPLEMENTATION OF BOOK PURChASING \\ PROCESS IN THE ERP SYSTEM}

\section{A. Purchasing Plan Making}

As for the library, the purchase has a lot to do with the existing literature and other useless inventory. The improper purchase process may make the useless literature has nowhere to go. Then the funds and resources cannot play its due role, which results in cost increasing [11]. Therefore, making effective purchase plans is essential in terms of cost. Purchase plans are shown as in Fig.2.

First, the library ERP platform reader information system and business management system analyze the main library service object and the type of readers, and get the specific requirements. Then, they can determine the goal of the library literature resources construction: public information security, circulation type, research or others, so that the main types of literature resources to be constructed is made sure. According to types of resources and the basic information of current suppliers in demand-supply information system, they can determine the short-term and long-term plan of purchase. The recent purchase plans can be detailed to one book or one copy book, while in the long-term purchase plans, the goal for increasing literature resources in each short period should be made clear.

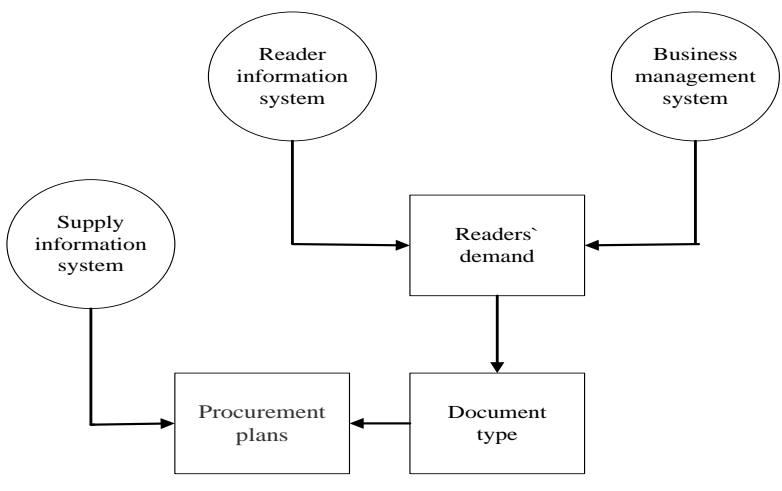

Figure 2. Purchase planning

\section{B. Good cooperation with suppliers}

The selection criteria of suppliers should cover the elements of goods supplied, such as price, quality and delivery date. A good supplier should not only provide the preferential price, timely delivery, adequate choices for the library literature acquisition, but also the related information and evaluation of all the transactions which can be found in the supply information system. Fig.3 shows a process of good cooperation between the library and the supplier.

The cooperation between library and the supplier has been receiving more and more attention, because it also embodies the idea of ERP. Before the final winning of the bidding, the library will make communications with cooperation suppliers for a full range of understanding the bookseller, which include the abilities of providing books and service. Then, it is sure that the literature provided by suppliers can improve the quality of library resources and the competition edge of the library can be improved [12]. After the literature resources are delivered, the evaluation archives should established and the previous transaction records should be built up so that information can be shared for the convenience of next cooperation. For the supplier, they implement the relevant agreement in a better way and promote the realization of the transactions with the best service, so the reputations will be greatly improved. It will play a decisive role in the next bidding. The win-win of library and supplier is based on the good cooperation.

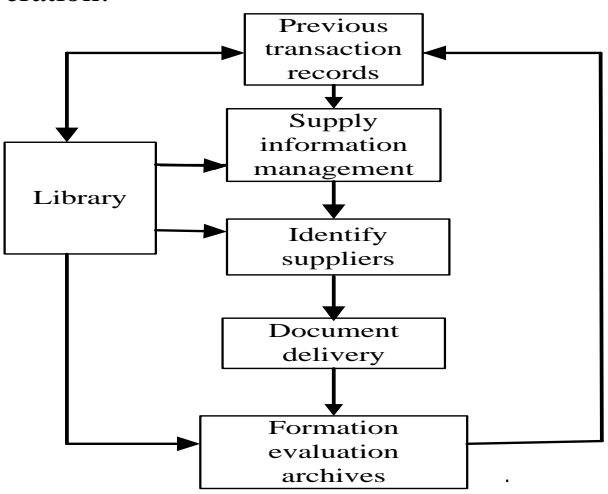

Figure 3. The process of cooperation between the library and the supplier 


\section{Order management in Library}

In ERP system, subscription management of library is very important. The purchasing process is managed in a dynamic way, which is based on the resources construction plan, the latest literature information, readers demand and a series of dynamic elements. The continuous updating of the knowledge and the raising of the reader requirements, the needs of library literature construction are changing. This forces the corresponding supplier to make adjustments and changes. At the same time, because of the existence of various suppliers, there are so many subscription books. Some of them are just repetitions of each other. So it seems to be very necessary to summary and check. Under the supervision of various departments, the electronic order will be sent to the supplier after summarizing, checking and approval by leaders. The process of order management is shown as in Fig.4.

Electronic order can also be seen by different departments or agency personnel, even in different stages of purchase process. All the departments and agencies make adjustments according to the situation at any time, and the supplier ensures delivery and shipment according to the order change at any time, which really embodies the idea of agile manufacturing.

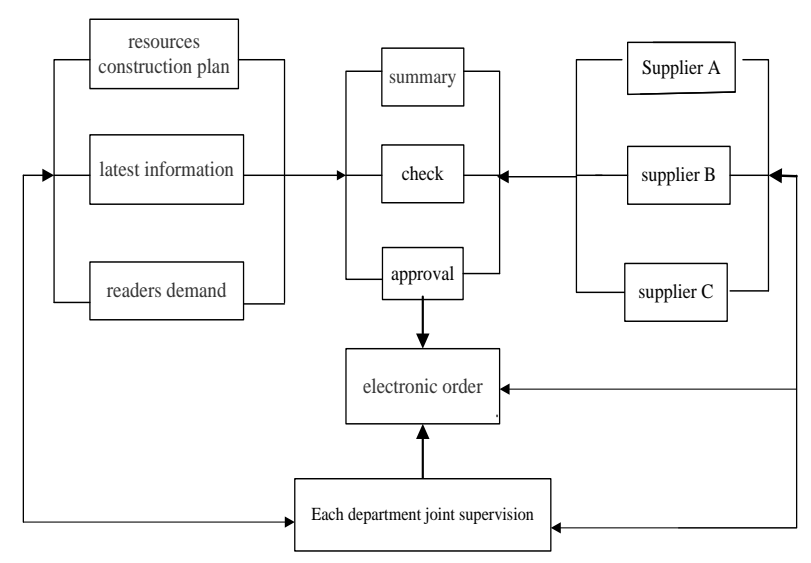

Figure 4. The process of order management

\section{Order Tracking and Expediting}

Order tracking refers to the relevant inspection, monitoring and liaison according to the execution schedule after the order is sent out. Purchasing librarians should pay attention to the trend and status of order, and maintain contact with suppliers, so as to avoid the errors in the generation and transmission of orders, providing security for the later cataloging and processing work. Timely expediting can also guarantee the arrival time of literature to some extent, and prevent the deliberate delay or no reporting of shortage. Order tracking and expediting can shorten the time of literature resources getting to the library, and ensure the normal operation and sufficiency of library literature. The process is shown as in Fig.5.

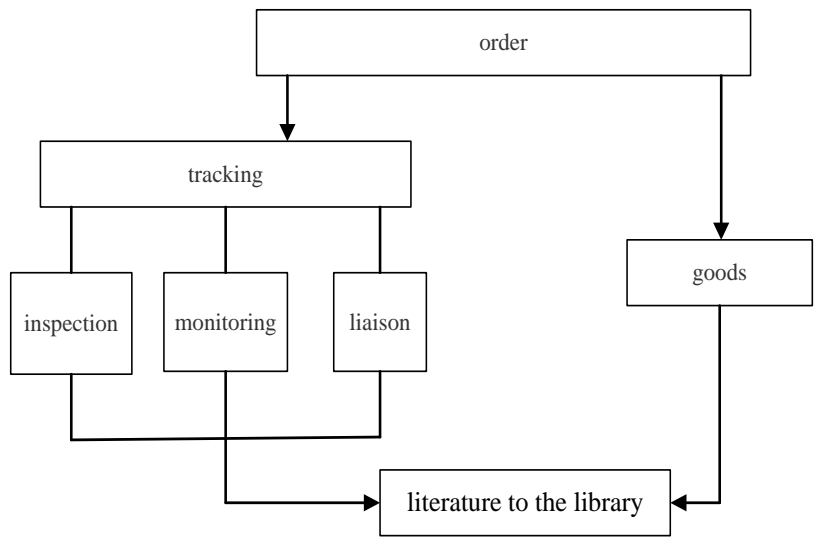

Figure 5. Order tracking and goods

\section{E. The acceptance of goods}

The acceptance of goods is the last link of the entire purchasing process, and it is also the beginning for the library to really realize the increase of collections. The acceptance process is shown as in Fig.6.

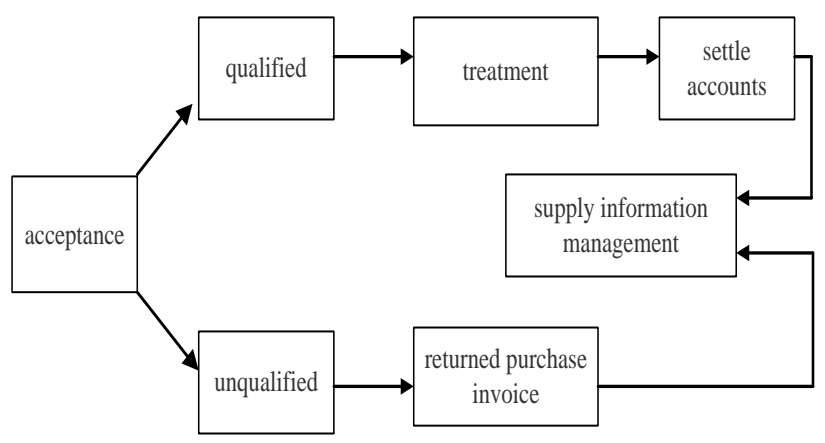

Figure 6. Acceptance process

The first step to build acceptance is often coarse acceptance, which includes checking the packing and the appearance of the products. It is difficult to open the package timely to check the list and books. If the supplier is reliable enough, this process may be omitted. Then the goods can be directly put into the library warehouse. What is real about library work is that several librarians spend a long time in checking the journals which are got to the library. They compare the periodical type, issues, price, appearance, the number of copies with what is on the order. Then the books getting to the library will be noted in the ERP system and the information about order will be sent to the financial department, which will be told to finish a series of tasks such as settling the accounts. If the book has a quality problem or is not what is ordered, they can return the book or require suppliers to provide new ones freely. The list to return the goods should be given immediately in the system. No matter how the result of 
checking is, the librarians should reserve the information in the management system.

\section{The IMPROVEMENT OF THE PURCHASING PROCESS OF LIBRARY UNDER ERP SYSTEM}

\section{A. Transparentizing of the Use of Funds}

ERP system makes the records of the capital flow and logistical records be kept in synchronization, and the data can be unified. Through the financial management system, comprehensive the financial status and understand the origin and whereabouts of the funds.

\section{B. To Reduce Purchase Costs}

The implementation of the ERP platform in the library purchase can greatly improve the convenience of obtaining all kinds of information for the purchasing librarians. The order information sources, which purchases librarians need for creating purchasing lists, can be obtained from ERP platform systems. They don't need to spend too much time collecting the information about user requirements and library collections, so the time cost of purchase operations can be reduced.

\section{Integrated Management of the System Users}

ERP system can help to realize the integration of information and management of human resources in the whole supply chain, which can be achieved by the system administrator by adding and controlling the users. There are various types of users in the open ERP system. Users can open an account, set permissions and expand permissions under the help of the system. The integrated management of the system users can promote the initiative of users and improve the work efficiency.

\section{Full Control of the Purchase Process}

The most humanized design in ERP system is that tags are added to each piece of information. This function is realized based on the alternate fields in the underlying database and can express in the system by relying on the powerful operation function of the large relational database. By adding tags in order and report, the librarians can control the whole process. In this way, the possibility of making reformations is realized whenever something is wrong.

\section{CONCLUSIONS}

In this paper, the purchase of library management system under ERP is studied. The authors introduce the book purchasing process based on ERP, study ERP system implementation of book purchasing process and analyze ERP system to improve the purchasing process of library.

\section{REFERENCES}

[1] Song Wei. Research and Realization on the Integration of PDM and ERP system Based on BOM [D]. Dalian University of Technology, 2005.

[2] Dai Minqing. The Modeling and Analysis of ERP System for Nonwovens Manufacturing Company [D]. Shanghai Jiaotong University, 2011.

[3] Fan Xingkun. The Application of ERP Managing Idea in Library Management [J]. Library and Information Service, No.6, 2002, pp.115-118, 107.

[4] Yue Xiuzhi, Liu Mingzhou, and Zhang Huaitao. Library Resource Planning (LRP) - A Research on the Mode of Library Digital Management System [J]. Industrial Engineering and Management, No.6, 2002, pp.46-49.

[5] Zhou Jian. The Countermeasure Research of the Implementation in the Library Based on ERP [J]. Journal of Modern Information, No.7, 2005, pp.143-144.

[6] Si Tukai. Thoughts and Methods on Improving Library's Acquisition Quality [J]. New Century Library, No.6, 2007, pp.27-28.

[7] Meng Shan, Ren Qing. Strategy on the University Library Book Selection Library Services Purchase [J]. Agriculture Network Information, No.12, 2013, pp.88-89,95.

[8] Qian Xia. The Design and Implement of Library Managemental System ERP [D]. University of Electronic Science and Technology of China, 2012.

[9] Qiu Qi. Study on the Application of ERP System in the Publishing House [D]. Shanghai International Studies University, 2014.

[10] Gu Bo. Study on Purchase Model Based on Library [J]. Heilongiiang Shi, No.1, 2011, pp.52-53.

[11] Wang Hua. Discussion on the Management Literature Acquisitioning of University Library in ERP from Microeconomics [J]. Journal of Information, No.10, 2003,pp.100-102.

[12] Meng Shan, Ren Qing. Strategy on the University Library Book Selection Library Services Purchase [J]. Agriculture Nerwork Information, No.12, 2013, pp.88-89,95. 